Voix et Images

volxetimages

\title{
Smith Conundrum. Un roman satirique sur McGill University
}

\section{Marc Angenot}

Volume 3, numéro 1, septembre 1977

Nicole Brossard

URI : https://id.erudit.org/iderudit/200101ar

DOI : https://doi.org/10.7202/200101ar

Aller au sommaire du numéro

Éditeur(s)

Les Presses de l'Université du Québec

ISSN

0318-9201 (imprimé)

1705-933X (numérique)

Découvrir la revue

Citer cet article

Angenot, M. (1977). Smith Conundrum. Un roman satirique sur McGill

University. Voix et Images, 3(1), 162-165. https://doi.org/10.7202/200101ar d'utilisation que vous pouvez consulter en ligne.

https://apropos.erudit.org/fr/usagers/politique-dutilisation/ 


\section{Smith Conundrum}

\section{Un roman satirique sur McGill University}

On redécouvre en France depuis 1972 l'œuvre romanesque de Régis Messac (1893-1945). Les éditions J.-C. Lattès viennent de rééditer les deux romans de science-fiction qu'il avait publiés avant la seconde guerre mondiale: Quinzinzinzili (1934), et la Cité des asphyxiés (1938).

Le même éditeur a également fait paraître en 1973 une singulière nouvelle utopique de Messac, Valcrétin, qui était restée inédite. Enfin, un pamphlet sur la guerre, la défaite et la bourgeoisie pétainiste, écrit en 1942, Pot-pourri fantôme, est également disponible aux éditions Bellenand.

L'œuvre romanesque de Messac offre plus d'un aspect attachant. Elle témoigne de la persistance d'une tradition de la contre-utopie et du récit conjectural entre les deux guerres, époque mal connue, considérée comme période "creuse" pour la SF française. L'imagination baroque et grimaçante de Messac, son sens de la satire sociale, ses audaces spéculatives et le non-conformisme de ses vues d'avenir font de ses romans des écrits qui égalent et surpassent les Maurice Renard et les Jacques Spitz, ses contemporains, et qui soutiennent la comparaison avec les écrivains américains de l' «âge d'or» de la SF.

Si l'œuvre d'imagination de Messac était restée ignorée jusqu'à tout récemment, ses travaux de critique et de sociologie littéraires sont mieux connus. Sa thèse monumentale sur le "Detective-novel" et l'influence de la pensée scientifique (1929) fait encore autorité et constitue une source irremplaçable de documents, d'analyses et d'hypothèses dans le champ des littératures populaires et marginales. Elle demeure à ce jour la seule recherche en para-littérature qui ait valu le doctorat d'État à son auteur. Parmi ses travaux de littérature comparée, on retiendra surtout son essai sur les Influences françaises dans l'œuvre d'Edgar A. Poe (1930). Il fut également le premier à étudier, avec une rigueur et une originalité intellectuelles qui étonnent pour l'époque où il écrit, la science- 
fiction et le roman utopique et conjectural. Ses monographies sur les récits de l'infiniment grand et l'infiniment petit (Micromégas, 1936) et sur le roman préhistorique (les Romans de l'homme-singe, 1935) retiennent d'autant plus l'attention qu'elles n'ont pas encore d'équivalent en domaine français où une étroite conception de l'imagination littéraire, une méfiance invétérée pour le prétendu «merveilleux scientifique" font tenir en suspicion une production nationale pourtant vaste et originale.

Créateur et théoricien, «précurseur" (ce terme galvaudé s'applique ici congrûment), Régis Messac mérite donc l'intérêt grandissant qui est né récemment autour de son nom.

Arrêté pour faits de résistance par les nazis en 1943, Messac est mort quelque part en Allemagne en 1945. II laissait une cuvre inachevée, plusieurs romans inédits, des études de socio-critique, Recherches sur le roman populaire, Essais de morphologie littéraire, dont une seule a été publiée ultérieurement, sa Chrono-bibliographie des Utopies (Lausanne, 1962). D'autres essais restent aujourd'hui dispersés dans diverses revues, certaines d'un accès difficile, comme le mensuel politique et littéraire les Primaires, dont il fut le rédacteur en chef de 1930 à 1940, et où apparaît un Messac nouveau qui complète l'image que l'on peut avoir de lui: commentateur politique, pamphlétaire vigoureux dont la défense des doctrines anarchistes s'exprime en des libelles d'une rare violence polémique qui font penser au meilleur Zo d'Axa...

Le but de la présente notice n'est pas cependant de tracer uniquement un tableau rapide de l'œuvre d'un grand utopiste méconnu.

Un de ses romans concerne directement l'Université McGill; la façon dont ce roman est venu à notre connaissance est elle-même des plus romanesques.

Messac a été professeur à l'Université McGill, au Département de langues romanes, de 1924 à 1929. Il venait de Glasgow où il avait été lecturer. La mort d'un de ses enfants, dans de tragiques circonstances, l'amena à regagner la France en 1929. II poursuivit sa carrière à Montpellier. En 1942, en pleine guerre et quoique absorbé par le réseau de résistance dont il s'occupait, il fit paraître chez un petit éditeur-bibliophile "l'Amitié par le livre» un roman, Smith Conundrum Sniversity, qui est le récit satirique de son séjour comme professeur de français dans notre Université.

Rien d'étonnant à ce que ce livre soit resté entièrement inconnu. Tous les exemplaires disponibles furent saisis et mis au pilon par les nazis en 1943 et les quelques volumes qui subsistaient furent détruits en 1945 lors de la prise de Querqueville (Orne) par les forces américaines. II semble qu'il n'en subsiste aujourd'hui que deux ou trois exemplaires que l'on peut dire miraculeusement préservés. 
Nous avons eu en main l'un de ces exemplaires:

Régis MESSAC,

“Smith Conundrum». Roman d'une université américaine.

[Paris], L'Amitié par le livre, [1942]; un vol. in -16, 169 p., daté «octobre 1930 - février 1931 ".

Le récit se présente comme une satire, parfois attendrie, souvent féroce, de la vie académique à l'Université McGill vers 1930.

L'anecdote en est assez mince: un jeune professeur de lettres peu conformiste s'attire d'innombrables difficultés avec la hiérarchie universitaire et notamment avec son Chairman, l'ineffable Vicomte du Boys de la Tour. Incapable de supporter le spectacle de servilité et de charlatanisme à quoi se réduit, selon l'auteur, la vie académique, il envoie sa démission au Board of Governors. Le roman est avant tout le prétexte à une série de portraits et d'anecdotes. Doué d'un sens aigu du pamphlet, Messac transcrit d'une plume alerte mais trempée dans le vitriol de petites "scènes vues" et trace les silhouettes caricaturales du prof. Talkinghorse (un Houyhnhnm ?), "Parsley Professor of Ethics and Moral Philosophy", du prof. Alexander J. Snuffbok, Ph. D., auteur d'une thèse sur «George Washington's Tactics at Great Meadows (VIII-59 p.) ", du Révérend Minus Hubbins, M. Th., et des piliers du Département de français, le prof. Dubois et le prof. Léon de Ribassier de Pivres. Tout ceci, très drôle, très enlevé, mais sans indulgence, il faut l'avouer.

La satire toutefois ne reste pas au niveau superficiel de la caricature. Une réflexion amère et souvent très dure sur la condition professorale se fait jour. Elle peut se résumer dans la phrase désabusée qui tombe des lèvres du professeur Addison, le confident du héros: "We are a sort of higher club servants. Subjects to dismissal, just like other servants..." On jugera peut-être par là que la pochade de Régis Messac n'est pas exempte d'une certaine actualité polémique.

Quoi qu'il en soit, le don d'observation incisif dont il fait preuve, le sens du raccourci, du "gag", du burlesque font de Messac un humoriste qui fréquemment semble se souvenir de Stephen Leacock dont il admirait l'œuvre, même s'il n'a pas la sérénité de ce dernier. Il n'est pas besoin de considérer Smith Conundrum comme une cuvre à clé pour trouver du plaisir à lire ce récit. On y verra cependant certains détails qui paraîtront peut-être familiers : l'ordinaire du Faculty Club n'est toujours pas susceptible de satisfaire des gastronomes exigeants et le service des commandes de la bibliothèque semble avoir, dès 1924, présenté des bizarreries de fonctionnement.

On ne peut que souhaiter que ce roman dont les événements dramatiques ont empêché la diffusion puisse connaître un jour une réédition qui serait, en fait, la première édition véritable. 


\section{Bibliographie}

À bas le latin! (pamphlet), s. 1., 1934.

Le "Detective-novel " et l'influence de la pensée scientifique, Paris, 1929.

Influences françaises dans l'œuvre d'Edgar Poe, Paris, 1929.

Micromégas, Nîmes, 1936.

Néamia (roman), s. 1., s. d.

Pot-pourri fantóme, Paris, 1958.

Les Primaires, revue mensuelle, Paris, 1922-1940.

Quinzinzinzili (SF), Paris, 1972.

La Révolution culturelle, Paris, 1938.

Les Romans de l'homme-singe, Paris, 1935.

Smith Conundrum (roman), s. 1., 1942.

Valcrétin (SF), Paris, 1973.

En outre, diverses brochures, des traductions de romans anglais, des articles de critique littéraire et les manuscrits inédits dont il est question plus haut.

Marc Angenot 


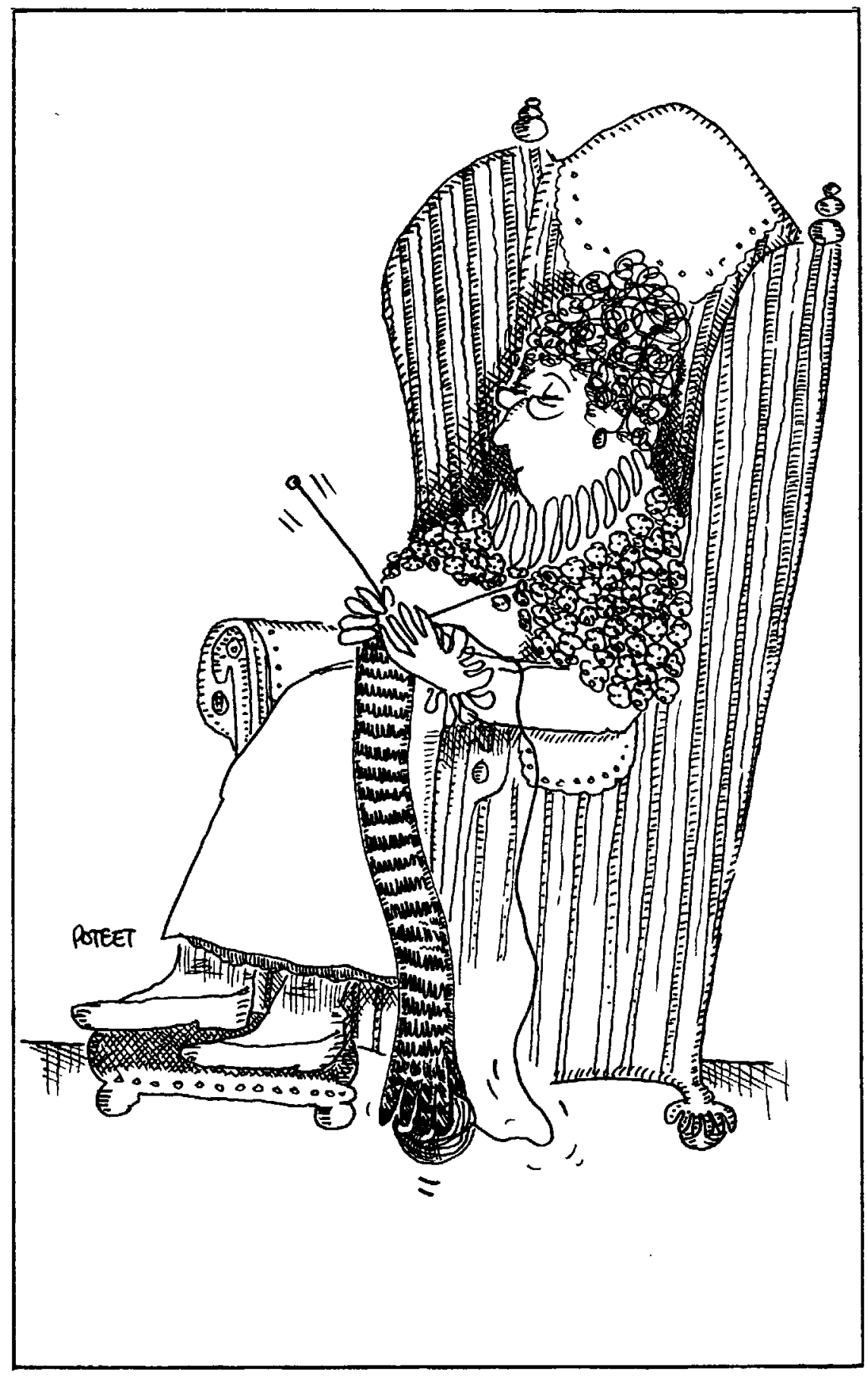

